\title{
In Retrospect: Can BST Models be Reinterpreted for What Decisions, Speciation Events and Ontogeny Might Have in Common?
}

\author{
Niko Strobach
}

\begin{abstract}
This chapter addresses two interrelated topics: (1) a formal theory of biological ancestry (FTA); (2) ontological retrospect. The point of departure is a reinterpretation of Nuel Belnap's work on branching spacetime (BST) in terms of biological ancestry. Thus, Belnap's prior choice principle reappears as a principle of the genealogical unity of all life. While the modal dimension of BST gets lost under reinterpretation, a modal dimension is added again in the course of defining an indeterministic FTA where possible worlds are alternatives in terms of offspring. Indeterministic FTA allows to model important aspects of ontological retrospect. Not only is ontological retrospect a plausible account for the perspectival character of Thomason-style supervaluations, but it is shown to be a pervasive ontological feature of a world in development, since it is relevant for cases as diverse as speciation, the individual ontogeny of organisms and decisions of agents. One consequence of an indeterministic FTA which includes the idea of retrospect is that, contrary to what Kripke famously claims, species membership is not always an essential feature, but may depend on the way the world develops. The chapter is followed by a postscript by Martin Pleitz and Niko Strobach which provides a version of indeterministic FTA that is technically even closer to Belnap's BST than the one in this chapter and which allows for a discussion of further philosophical details.
\end{abstract}

\section{Introduction}

This chapter is about a subclass of the structures which Nuel Belnap defined in his epoch-making 1992 article "Branching space-time"1 (BST) and which have, therefore, been called BST structures ever since. BST structures have triggered an

\footnotetext{
${ }^{1}$ Belnap (1992).

\section{N. Strobach $(\bowtie)$}

Westfälische Wilhelms-Universität Philosophisches Seminar, Domplatz 6,

48143 Münster, Germany

e-mail: nstro_01@uni-muenster.de
} 
impressive amount of interesting research. Still, as far as I'm aware, this chapter provides a novel interpretation of them. The reinterpretation is in terms of biological ancestry and links BST with the philosophy of biology. The present chapter is followed by a postscript, which was co-authored by Martin Pleitz and Niko Strobach. The postscript ties the modal version of the theory of ancestry even more closely to BST structures than the present chapter does and thus draws attention to a number of important features of a modal formal theory of biological ancestry which are not discussed in the present chapter.

In what follows, the suggested reinterpretation of BST structures will be expanded in certain respects. Thus, it is possible to link two relatively independent topics. One topic is a formal theory of biological ancestry, the other is ontological retrospect.

I shall proceed in two steps. In a first step, certain kind of BST structures will be reinterpreted as a certain kind of structures of the formal theory of ancestry (in what follows: FTA). I shall then briefly explain what can be done with FTA structures. The most characteristic feature of BST structures is the so-called prior choice principle. It will turn out that the prior choice principle corresponds precisely to a particularly important and intuitively controversial feature that may be added to FTA: the postulate of the unity of life. The fact that maximal directed subsets (MDSs) of BST structures may "branch" is crucial to the original space-time interpretation, because it is interpreted as modal branching of spatio-temporal histories. This modal character of MDSs is lost when those BST structures, which are suitable for FTA interpretation, receive a biological interpretation.

So, in a second step, I suggest adding the modal dimension again. Roughly, I will have structures of FTA play the role of histories in the original interpretation of BST structures.

This allows me to address the topic of retrospect. My main claim is that, at least sometimes, retrospect is not an epistemological, but an important ontological feature of reality which has, so far, been neglected. Finding this plausible presupposes pretty strong intuitions in favour of the temporal A-series. ${ }^{2}$ If ontological retrospect appears plausible in itself, this will, by contraposition, provide some further support for an A-theoretical view of time.

I shall point out that ontological retrospect calls into doubt Kripke's thesis that belonging to the biological species to which one belongs is an essential property. I shall then point out how one might transfer the idea of retrospect to the very beginning of life. I shall consider retrospect in connection with speciation and in connection with the ontogeny of individual living beings (which might have implications for moral philosophy).

I conclude by indicating how decisions fit into the picture, a topic on which Nuel Belnap has made such an important contribution by developing STIT-models and by co-authoring Facing the Future. ${ }^{3}$

\footnotetext{
2 Cf. McTaggart (1908).

${ }^{3}$ Belnap et al. (2001).
} 


\section{First Step: BST Structures and Structures of FTA}

\subsection{BST Structures}

As is familiar to readers of Belnap's BST, a BST structure is an ordered pair which consists of a nonempty domain $\mathrm{D}$, usually interpreted as a set of possible point events, and an accessibility relation $\leq$, usually interpreted as possible causal-influence-oridentity, which satisfies a number of postulates. In order to conveniently formulate the postulates, the following definitions are needed ${ }^{4}$ :

\begin{tabular}{|c|c|}
\hline \multirow{3}{*}{$\begin{array}{l}\text { Definition }< \\
\text { Definition directed subset }\end{array}$} & \\
\hline & $\mathrm{m}$ is a directed subset over $\langle\mathrm{D}$, \\
\hline & $\begin{array}{l}\mathrm{D} \text { in } \mathrm{m} \text { there is a } \mathrm{z} \text { from } \mathrm{D} \text { in } \mathrm{m} \text { such that } \\
\mathrm{x} \leq \mathrm{z} \& \mathrm{y} \leq \mathrm{z}(B S T \mathrm{D} 4)\end{array}$ \\
\hline Definition history / MDS & $\begin{array}{l}\mathrm{h} \text { is a history over }\langle\mathrm{D}, \leq\rangle \text { iff } \mathrm{h} \text { is a maximal directed } \\
\text { subset over }\langle\mathrm{D}, \leq\rangle(B S T \mathrm{D} 5) ;\end{array}$ \\
\hline Definition obviously undivided & $\begin{array}{l}\text { histories } \mathrm{h} \text { and } \mathrm{h}^{\prime}(\text { over }\langle\mathrm{D}, \leq\rangle) \text { are obviously } \\
\text { undivided at } \mathrm{x} \text { (from } \mathrm{D}) \text { iff there is a } \mathrm{y} \text { from } \mathrm{D} \text { such that } \\
\mathrm{y} \in \mathrm{h} \& \mathrm{y} \in \mathrm{h}^{\prime} \& \mathrm{x} \leq \mathrm{y}(B S T \mathrm{D} 18) \text {; }\end{array}$ \\
\hline Definition c[hoice] point & $\begin{array}{l}\mathrm{x}(\text { from } \mathrm{D}) \text { is a choice point between } \mathrm{h} \text { and } \mathrm{h}^{\prime} \text { iff } \\
\left\{\{\mathrm{h}, \ldots\}, \ldots,\left\{\mathrm{h}^{\prime}, \ldots\right\}\right\} \text { is the finest partition of histories } \\
\text { which contain } \mathrm{x} \text { such that any } \mathrm{h}^{\prime \prime}, \mathrm{h}^{\prime \prime \prime} \text { from any element of } \\
\text { the partition are obviously undivided at } \mathrm{x}(\text { BST } \mathrm{D} 19-21,24)\end{array}$ \\
\hline
\end{tabular}

The BST postulates are ${ }^{5}$ :

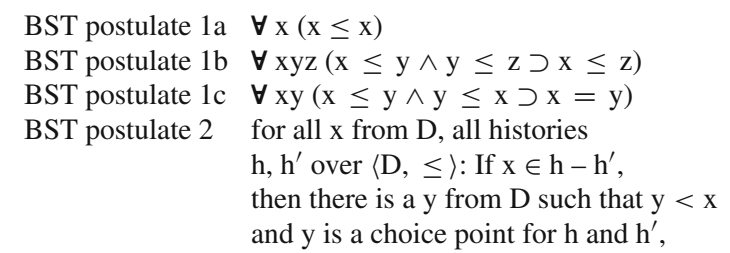

and $\mathrm{y}$ is a choice point for $\mathrm{h}$ and $\mathrm{h}^{\prime}$,

[reflexivity]

[transitivity]

[antisymmetry]

[prior choice principle/PCP]

\subsection{BTA Structures}

Now let us isolate some core of a formal theory of ancestry (FTA). Let us call it the basic theory of ancestry: BTA. BTA structures are based on a two-place relation $<$.

\footnotetext{
${ }^{4}$ Belnap (1992), 390, 409.

${ }^{5}$ Postulates 1a to 1c are called postulate 1, postulate 2 is called postulate 28 in Belnap (1992), D is called OW.
} 
Just in order to be able to read the formulae let us say that " $<$ " is read "is an ancestor of". Let us add the following definitions ${ }^{6}$ :

$\begin{array}{lll}\text { Definition }>\mathrm{x}>\mathrm{y} \text { iff } \mathrm{y}<\mathrm{x} & \text { [descendant] } \\ \text { Definition } \geq \mathrm{x} \geq \mathrm{y} \text { iff } \mathrm{y} \leq \mathrm{x} & \text { [descendant or identical] } \\ \text { Definition } \gg \mathrm{x} \gg \mathrm{y} \text { iff } \mathrm{x}>\mathrm{y} \wedge \sim \exists \mathrm{z}(\mathrm{x}>\mathrm{z} \wedge \mathrm{z}>\mathrm{y}) & \text { [direct descendant] }\end{array}$

\section{Definition "BTA structure":}

A BTA structure is an ordered pair which consists of a nonempty and finite domain $\mathrm{D}$ and an accessibility relation $<$ that satifies the following postulates ${ }^{7}$ :

BTA postulate $1 \quad \forall \mathrm{xy}(\mathrm{x}<\mathrm{y} \supset \sim \mathrm{y}<\mathrm{x}) \quad$ [asymmetry, thus irreflexivity]

BTA postulate $2 \forall \mathrm{xyz}(\mathrm{x}<\mathrm{y} \wedge \mathrm{y}<\mathrm{z} \supset \mathrm{x}<\mathrm{z}) \quad$ [transitivity]

Postulates 1 and 2 postulate a partial strong order on $\mathrm{D}$ with respect to $<$. Postulating a finite domain has at least the following consequences ${ }^{8}$ :

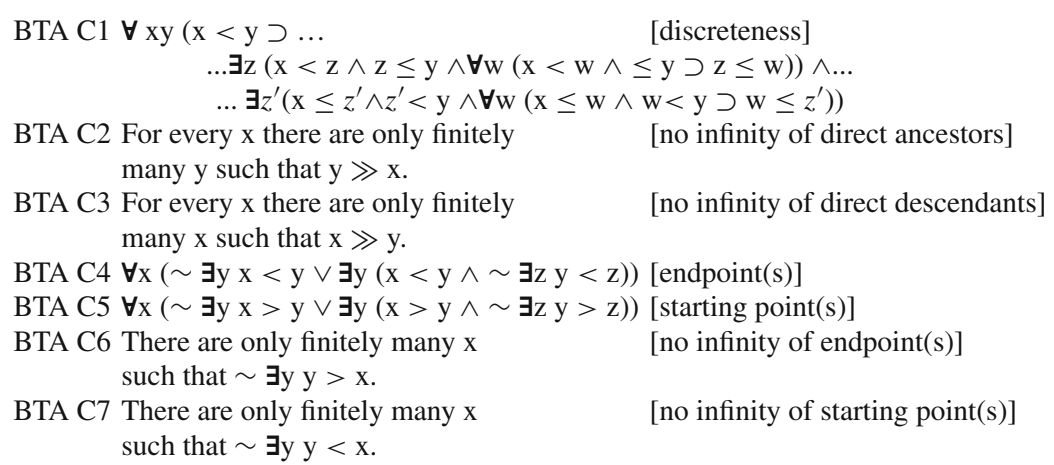

\footnotetext{
${ }^{6}$ Martin Pleitz has pointed out to me that, alternatively, it should be possible to base BTA structures on a primitive relation of direct ancestry or direct descent and to introduce a more general relation by definition. However, the results of both approaches do not to seem to be interdefinable in any simple and obvious way. One reason is the case of Antigone: On the alternative approach, Antigone would clearly have two direct ancestors. Possibly, the alternative approach is closer to branching space-time models which are based on local transitions (cf. Müller 2011) than to the models of Belnap (1992).

${ }^{7}$ Strobach $(2010,2011)$ contain the same postulates, except postulate 3, which is there presented in a weaker version which I now consider slightly too weak.

${ }^{8}$ Regarding BTA C1, cf. Goranko et al. (2004), 15. The formula means: To each ancestor x of y there is (1) some descendant $\mathrm{z}$ such that any $\mathrm{w}$ after (ancestor-wise) $\mathrm{x}$ and up to $\mathrm{y}$ is $\mathrm{z}$ at the earliest, and (2) there is some descendant z' such that any $\mathrm{w}$ after $\mathrm{x}$ from $\mathrm{x}$ on and before $\mathrm{y}$ is $\mathrm{z}^{\prime}$ at the latest.
} 
In what follows, BTA C1 to C7 will also be called the finiteness postulates. Note, however, that even all of them together will not guarantee a finite domain. ${ }^{9}$ Although I think that BTA is basic, $\mathrm{C} 1$ to $\mathrm{C} 7$ are, in a way, arranged in diminishing degrees of intuitive basicness: $\mathrm{C} 1$ to $\mathrm{C} 3$ are absolutely essential to a biological interpretation, giving up $\mathrm{C} 3$ and $\mathrm{C} 4$ is very hard to imagine on a biological interpretation. Intuitively, C4 and C5 look somewhat less basic, perhaps C4 even less than C5 (C4 and C5 are independent of each other). Given $\mathrm{C} 4$, it is very hard not to accept $\mathrm{C} 6$, and given $\mathrm{C} 5$, it is very hard not to accept $\mathrm{C} 7$ on a biological interpretation.

A BTA structure enriched by the postulate of the unity of all life (BTA+U) is a BTA structure that satisfies the following additional postulate which forbids isolated substructures:

$$
\begin{aligned}
\text { Postulate } U & \forall x y(x \neq y \supset(x<y \vee y<x \vee \ldots \text { [unity of life] } \\
& \ldots \exists z(z<x \wedge z<y) \vee \ldots \\
& \ldots \exists z(x<z \wedge y<z)) .
\end{aligned}
$$

\subsection{BTA+U Structures are BST Structures}

It is easily possible to establish the following purely formal result: The class of $\mathrm{BTA}+\mathrm{U}$ structures is a subclass of the class of BST structures. The proof uses finiteness, BTA C4 (endpoints) and postulate U (unity of life). Hurried readers might like to skip it and continue with Sect.2.4.

First, it is a standard result that the BST postulates 1a to 1c are equivalent to the postulates 1 and 2 of BTA. So in order to establish the mentioned result it is enough to show that the postulates for BTA+U imply the PCP.

Clearly, the BTA finiteness postulates could be added to the postulates of BST in order to single out a certain subclass of BST structures whose elements satisfy some extra constraints. BST structures need not be dense and may well contain "endpoints", i.e. some element $\mathrm{x}$ of D may satisfy $\sim \exists \mathrm{y} \mathrm{x}<\mathrm{y}$ or $\sim \exists \mathrm{y} \mathrm{y}<\mathrm{x}$. It is true that, according to the original intended interpretation of BST structures, both alternatives seem rather strange, the first even more so than the second, but they are not excluded. Let us note some facts first:

Fact 1: There is only one way for an MDS of BST/BTA to end: in a single endpoint (according to the space-time interpretation of BST: a single big crunch event). If a subset of a BST or a BTA structure has a spliced end it will not be a directed subset, because splicing precludes a common upper bound. So either an MDS of BST/BTA

\footnotetext{
${ }^{9}$ Take the positive integers in their usual order ( 1 being the first element) and the negative integers in reverse order ( -1 being the last element) and define that every positive integer precedes every negative one. This structure satisfies $\mathrm{C} 1$ to $\mathrm{C} 7$, but is infinite. It seems that finiteness is guaranteed by postulating finite chains.
} 
does not terminate at all, or it terminates in a single element of D. So each MDS of BTA terminates in exactly one element due to BTA C4.

Fact 2: Postulate U implies that any two MDSs intersect. For due to fact 1, every MDS terminates in exactly one element of D. But the endpoints of two different MDSs have no common upper bound. So in order to avoid a violation of postulate $\mathrm{U}$ they must intersect somewhere else below.

Fact 3: If some item e belongs to an MDS, so must any predecessor of e in terms of $<$. If $\mathrm{e}$ is a member of some MDS $\mathrm{h}$ and if $\mathrm{e}^{\prime}<\mathrm{e}$, then $\mathrm{e}^{\prime}$ is a member of $\mathrm{h}$, too. For if e is a member of $h$, but $e^{\prime}$ isn't, then there is a proper superset of h, i.e. $h \cup\left\{e^{\prime}\right\}$, which is a directed subset of D. For, by transitivity, every common upper bound of e and some $\mathrm{e}^{\prime \prime}$ from $\mathrm{h}$ is a common upper bound of and $\mathrm{e}^{\prime}$ and $\mathrm{e}^{\prime \prime}$, too. So $\mathrm{h}$ is no MDS, but was supposed to be one.

Now let $\langle\mathrm{D},<\rangle$ be a BTA $+\mathrm{U}$ structure, let $\mathrm{e}_{1}$ be an element of $\mathrm{D}, \mathrm{h}_{1}$ and $\mathrm{h}_{2}$ maximal directed subsets (MDSs) of $\mathrm{D}$ with respect to $\leq$. Assume the antecedent of the PCP, i.e. that $e_{1} \in h_{1}-h_{2}$. It is easy to see that $h_{1}$ and $h_{2}$ must be different from each other, and that $h_{2}-h_{1}$ is nonempty. So there is some element of $h_{2}-h_{1}$, which we may call $e_{2}$, which is different from $e_{1}$ and which does not belong to $h_{1}$.

Any two MDSs intersect. So $\mathrm{h}_{1}$ and $\mathrm{h}_{2}$ do. Clearly, neither $\mathrm{e}_{1}$ nor $\mathrm{e}_{2}$ is a common member of both of them. Can any successor of $\mathrm{e}_{1}$ be a common member of $\mathrm{h}_{1}$ and $h_{2}$ ? No, because if so $e_{1}$ would have to be a member of $h_{2}$, too. But we know e $e_{1}$ isn't a member of $h_{2}$. Analogously for $h_{1}$ and $e_{2}$. So there must be a common member of $\mathrm{h}_{1}$ and $\mathrm{h}_{2}$ which precedes both $\mathrm{e}_{1}$ and $\mathrm{e}_{2}$, call it $\mathrm{e}_{3}$.

Now, because of finiteness, there is a(t least one) last common <-predecessor of both $\mathrm{e}_{1}$ and $\mathrm{e}_{2}$, either identical with or after $\mathrm{e}_{3}$, say $\mathrm{e}_{\mathrm{c}}$.

Now consider the finest partition of all MDSs which contain $e_{c}$ such that it bundles obviously undivided MDSs at $\mathrm{e}_{\mathrm{c}}$. It must contain $\mathrm{h}_{1}$ in one of the bundles and $\mathrm{h}_{2}$ in another. So $\mathrm{e}_{\mathrm{c}}$ is a c-point for $\mathrm{h}_{1}$ and $\mathrm{h}_{2}$. Also, $\mathrm{e}_{\mathrm{c}}$ precedes $\mathrm{e}_{1}$. So there is a c-point for $h_{1}$ and $h_{2}$ which precedes $e_{1}$. So the consequent of the PCP is satisfied on the assumption that its antecedent is satisfied. So the class of BTA+U structures is a subclass of the class of BST structures.

\subsection{What Does it all Mean?}

Why reinterpret (some) BST structures in terms of living beings? What is the intended interpretation of FTA structures? Certain notions in contemporary biology cry out for formal modeling, in particular cladistic notions like "most recent common ancestor" (concestor) or "last universal common ancestor" (LUCA). ${ }^{10}$ In contemporary

\footnotetext{
${ }^{10}$ Some formal modeling of biology was attempted by the logically-minded biologist Joseph Henry Woodger between the 1930s and 1950s. Woodger makes some natural assumptions which are built into BTA, too. However, the FTA presented here (with BTA as its basic version) is without any reference to Woodger. Cf. Woodger (1937). Some summary of Woodger is contained in Carnap (1958). I am grateful to Barry Smith for drawing my attention to Woodger.
} 
bioinformatics, phylogenetic trees are usually reconstructed by using algorithms which include pretty specific constraints on branching structures, e.g. that every parent node has exactly two daughter nodes. ${ }^{11}$ That is fine for cladograms, but one should have something much more basic and more general which should yield the usual trees only after adding quite a lot of constraints.

The notions of concestor and LUCA presuppose that one species may be called the ancestor of another species. What this means is not quite as clear as one might wish. It is appropriate to start from the ancestor-relation between individual living beings. This is a relation we are well-acquainted with. The intended interpretation is quite broad, though: Not only are parents ancestors of their children, but also, literally, parent cells of daughter cells. ${ }^{12}$ We are well-acquainted with individual living beings, whose existence is beyond doubt (the same cannot be said of species). So our domain $\mathrm{D}$ is interpreted as containing living beings. They may be multicellular or unicellular, the size of a bacterium or the size of a whale, plant or animal, reproducing sexually or asexually. I shall not try to define what a living being is. My approach will, however, show some affinity ${ }^{13}$ towards a recursive definition with an ostensive base: "We are living beings, all ancestors of living beings are living beings and all descendants of living beings are living beings, and nothing else is a living being." The tricky bit is the final clause of the recursive definition "...and nothing else is a living being". I am sympathetic with it. No angels. And, as will become clear later on, no Martians either.

BTA contains no postulates which preclude forward or backward branching. Individual biological ancestry is a network. It possesses nothing like the maximally fine twigs of Prior's tempo-modal trees, even though the network of some BTA structure may, by and large, be tree-shaped, if you look at it from afar. Not only does a living being often have several direct descendants, but also several direct ancestors, in the case of sexual reproduction: usually two (but beware of Antigone!). ${ }^{14}$

BTA C4 and C5 deserve a little extra comment. C5 says that every living being has either no ancestor or is a descendant of some living being that had no ancestor. One might motivate this by saying that BTA structures are supposed to be local and that the primordial soup is out of focus. But although one might do so, I am rather up to some large-scale modeling of all the life that there has been so far. If life had been going on forever, as Aristotle thought, and, thus, the domain is infinite, BTA C5 would be false even on the largest scale (although even Aristotle would have allowed for starting points in the structure due to spontaneous generation). ${ }^{15}$ Even today,

\footnotetext{
${ }^{11}$ Cf. Gusfield (2007).

12 Even ancestors of endosymbionts may be called ancestors of what, in later generations, they will be endosymbionts in. That depends on what turns out to be the best description of the fusion of host cells and endosymbionts.

${ }^{13}$ I am not claiming that there is a one-to-one correspondence between this definition and postulate U. There isn't.

${ }^{14}$ Antigone has only one direct ancestor: Oedipus. For her mother, Iokaste, has a descendant, her son Oedipus, who is an ancestor of Antigone, i.e. her father.

${ }^{15}$ For a detailed comparison of Aristotelian and contemporary biology in terms of structural postulates cf. Strobach (forthcoming).
} 
we might wonder: Must there really have been ancestor-less living beings? Yes, wherever in the vague morning haze of evolution the horizon of life may be hidden. For suppose, BTA C5 were not true. Then there would be at least one topologically infinite lineage of living beings, which, since every reproductive step takes some finite time and there is some lower bound to the length of such a time, ${ }^{16}$ would also be metrically infinite. So there would have been living beings before big bang, which is absurd.

BTA C5 comes naturally along with BTA C7: There is no infinity of ancestor-less living beings. They neither presuppose nor preclude one single ancestor-less living being, the one and only primordial cell. It is probable that the primordial soup was boiling on more than one stove. Life grew together. ${ }^{17}$

The least obvious principle is BTA C4: Every living being has either no descendants or is an ancestor of some living being that has no descendants. This makes BTA structures topologically finite towards the reproductive future. One might motivate this by the fateful certainty of the sun running out of fuel some day in the future, or by big crunch or big chill scenarios. Large-scale modeling can be depressing. My reason for BTA C4 is rather pragmatic: let us model life up to now. Or up to any time in the past we choose (as long as it contains life). Remember, by the way, that the overwhelming majority of all living beings that ever existed never reproduced, which already makes for lots of endpoints in a BTA structure. MDSs of BTA structures, on the biological interpretation, are just the set of all ancestors of some descendant-less living being.

No temporal sequence is modeled directly. No life-spans are modeled. There is no way to express the fact that individual lives are finite. It is true that remote ancestors will not coexist with their remote descendants. But there isn't even so much simultaneity modeled in a BTA structure to express this.

\subsection{The Unity of Life}

Postulate $U$ had better be separated from the basic parcel of axioms which have been explained. "U" is supposed to abbreviate "unity of life", and that is what it is about on the intended interpretation. It says: Any two living beings are related by the ancestor relation (one way or the other) or have a common ancestor or have a common descendant.

Note that the class of BTA structures without restrictions is not a subclass of the class of BST structures. The class of BTA structures contains structures in which some maximal directed subsets do not intersect. This cannot happen with a BST structure. On the usual BST interpretation this would mean that there are several causally unrelated bundles of histories, several parallel universes with all their modal

\footnotetext{
16 The last clause precludes, as Martin Pleitz put it in conversation, "inverse Thomson lamps".

17 There is some tension between BTA C5 and postulate U, if there is no single primordial cell. It will be resolved later on, in the section on retrospect.
} 
branching, which are part of the same structure. On the intended large-scale BTA interpretation this would mean that there are several independent trees or networks of life.

My own point of view on the matter is a bit complicated. I am not even entirely happy with the prior choice principle on the original BST interpretation. ${ }^{18}$ Although I am against postulating the prior choice principle in the manner of Belnap (1992) if one interprets BST structures the usual way, I prefer BTA+U to BTA without U. However, in discussions the following points have been raised against postulate $\mathrm{U}$ :

(1) Postulates of a supposed FTA should be conceptual truths, uncontroversial truths about the use of the word "life". But it does not belong to the meaning of the word "life" that all life is genealogically coherent.

(2) If we met Martians pretty similar to us, but genealogically completely unrelated to us, how could we possibly deny that they are living beings?

So it seems that the largest plausible scale of an intended interpretation of a $\mathrm{BTA}+\mathrm{U}$ structure can be life-on-earth.

However, as to (1), I am not sure if there are such things as conceptual truths independent of any background theory. If not, why not take the best background theory we have today? Of course, this does not yet settle the point. Did 20th century biology discover the unity of all life? Is this anything a science can empirically discover? If so, how about the Martians?

I want the Martians out. I tend to deny that they are living beings. Both objections to postulate $\mathrm{U}$ might be symptoms of a profound misunderstanding of how the word "life" should be understood. Defining the word "life" by a set of criteria has never really worked. It rather seems that if any term works like a natural kind term the way Kripke thinks, then "life" is a good candidate for a natural kind term. In fact, "life" might even work better as a natural kind term than the species terms of traditional biology or folk biology. It is a very amazing fact that what we have been pointing to as life all the time has indeed turned out to be one kind of thing. "Life" might even be a proper name that refers to a single object which is coherent in four-dimensional space-time. That does not necessarily contradict its being a natural kind term. Even natural kind terms like "gold" might best be interpreted as proper names, not just as

\footnotetext{
18 Strobach (2007a), 219ff. Recent work by Müller (2011) and by Tomasz Placek (in the present volume) on BST has refrained from postulating choice points in the manner of Belnap (1992) in order to make BST more "GR-friendly" (GR = general relativity), for first points of divergence suit GR topology better than last points of coincidence. I think that there are independent metaphysical reasons for preferring first points of divergence: branching is nothing that takes place, but world history develops by zillions of local decisions and thus continuously excludes possible alternative developments it might have had by the course it takes. Decisions do not take place at instants/events but by events occurring and thus not failing to occur. That picture suggests first points of divergence. So I welcome the result BST research has reached for different reasons than the ones I gave in Strobach (2007a). I suspect that if the PCP is abandoned, also the inclusion of the "wings" as a necessary feature of BSTs is gone (I would welcome this, too). At least the proof of fact 31 given in Belnap (1992), 411, seems to rely on the PCP.
} 
something close to proper names. ${ }^{19}$ We might owe the Martians some respect if they are capable of suffering, though. Still, I do not think they would be living beings if "life" is the kind of term I think it is.

There are, however, at least two serious counter-objections to postulate U.

(1) Why not fix the reference of the term "life" by pointing to life on planet earth and find more of it on Mars? Maybe the Martians and us would be like $\mathrm{H}_{2} \mathrm{O}$ and XYZ if they did not share the same microchemistry with us. But what if the Martians do not just look alive, but even share their microchemistry with us, while it is beyond doubt that we have no common ancestors with them? So at most, postulate $\mathrm{U}$ can be is a risky and contingent assumption.

(2) How can "early" sections of a BTA+U model without a primordial cell, when life has not yet grown together, be models of life? But if a BTA+U structure is supposed to be a model of life, how can an early, incoherent, section of it fail to be one? ${ }^{20}$

The second objection can only be dealt with in the section on retrospect. As to the first objection: Wouldn't we say that the situation in which the Martians even have DNA etc. would be one where life on earth clearly isn't all the life there is? That is not so clear. One might even consider dismissing the scenario as just too silly. However, dismissing any scenario which structurally resembles the one with Martian DNA as just too silly, would be too easy a way out. The progress of socalled synthetic biology might soon cause a situation which is, in principle, not too dissimilar from the scenario. As long as existing cells are reprogrammed, postulate $\mathrm{U}$ remains plausible. Once cells with the same microchemistry as life can be built from the scratch, postulate $U$ might have to be reconsidered. My opinion is that one should be on the cautious side when it comes to calling them instances of life. At least we should be clear about the fact that we might be facing a fundamental conceptual decision in a few years and that subsuming artificial cells under the term "life" is not a matter of course. Furthermore, clearly, if there is some essential property which

\footnotetext{
${ }^{19}$ The relevant passage is Kripke (1980), 127: "[T]erms for natural kinds are much closer to proper names than is ordinarily supposed. The old term 'common name' is thus quite appropriate for predicates marking out species or natural kinds, such as 'cow' or 'tiger'. My considerations apply also, however, to certain mass terms for natural kinds, such as 'gold', 'water', and the like." But neither "gold" nor "tiger" is a predicate. "...is a portion of gold" and "...is a tiger" are. "Gold" and "tiger" are singular terms. They are proper names for natural kinds, not just something close to names, while natural kinds are individual elements of the universe of discourse.

${ }^{20}$ As Martin Pleitz has remarked to me in conversation, there are even extreme cases in which a structure may "lose" the property of satisfying postulate U again by acquiring an additional descendant. Think of expanding an $\mathrm{N}$-shaped structure with ancestry downward into an M-shaped structure. This shows that postulate $\mathrm{U}$ is very strong. Still, I do not think it is unrealistically strong. Why is it so strong anyway? It is not only related to the PCP, but it is the minimal condition you need for, once an object language has been defined, being able to highlight the whole structure from a certain context by using sequences of quantifier-like modal operators without the help of actuality operators. In fact, postulate $\mathrm{U}$ came to my mind as a constraint on models of modal logic in connection with Crossley and Humberstone (1977) investigation of "actually" and Kienzle (2007) investigation of non-isolated structures of modal logic. This does, of course, not help its philosophical motivation.
} 
$\mathrm{a}$ and $\mathrm{b}$ share, $\mathrm{a}$ and $\mathrm{b}$ need not be numerically identical. Any two different human beings in 2013 might serve as a counter-example. So even if being DNA(etc.)-based were an essential property of both life (i.e. life on earth) and of the Martians' way of being, that would not force somebody to admit that there was life on Mars, too. Life might be very special in a combination of a number of respects, describable or not even describable; or it might be special just due to its very continuous history, which might be termed the maximal biography.

Suffice it to say that the question of the status and the acceptability of postulate $U$ is not easily settled and involves fundamental conceptual issues concerning the word "life". Interestingly, of all the conceivable postulates of FTA, the one that raises the most difficult questions is the one that formally corresponds to Nuel Belnap's prior choice principle.

\subsection{What Else Can be Done with BTA?}

Here is some very brief impression of what else can be done on the basis of BTA. ${ }^{21}$

(1) Independently of U, BTA structures may be expanded to BTA +CS by adding a second primitive relation, the relation of being conspecific, i.e. of being of the same species. Conspecifity should be postulated as symmetric, but not as reflexive (if mules don't belong to any species, no mule is conspecific with itself). It is also plausible to postulate that if a living being is conspecific with itself then there is some other living being with which it is conspecific (i.e. that nothing is sui generis). The transitivity of conspecifity is a tricky issue. It ensures that no living being belongs to more than one species in a BTA+CS model. However, a transitivity postulate might cause trouble in connection with ring species (like the sea-gulls around the arctic) or with historical borderline cases.

(2) Somehow the members of a species extension cohere genealogically. This would even be the case if life as a whole did not. So, quite independently of postulate U, an analogue of postulate $U$, and thus, again, of the prior choice principle, should be postulated. However, the simple analogue to postulate $U$ does not suffice for the kind of genealogical coherence one has in mind for the members of a species. For it does not preclude alien intermediate generations and is, thus, not tight enough to conform to our intuitions. However, some additional postulate does the job. ${ }^{22}$

(3) It is possible to give a clear account of what it means that a species is an ancestor of some other species in the context of a BTA+CS structure. Take the following definition:

\footnotetext{
${ }^{21}$ Points 1 to 5 are discussed in detail in Strobach (2011), point 6 is the topic of Strobach (2010).

${ }^{22}$ I suggest: "If $\mathrm{x}$ is a conspecific ancestor of $\mathrm{y}$, then $\mathrm{x}$ has a direct descendant that is conspecific with both $\mathrm{x}$ and $\mathrm{y}$ and which is an ancestor of or identical with y." Cf. Strobach (2011).
} 
A biological species $\mathrm{s}$ is a species ancestor of some biological species s " iff

(1) every organism that belongs to $s^{\text {' }}$ is a descendant of some organism that belongs to $\mathrm{s}$ and

(2) no organism belonging to $\mathrm{s}$ is a descendant of any organism that belongs to $s^{6}$.

BTA + CS provides the resources to explain why the relation which is thus defined is an ancestor relation: It satisfies the conditions which were postulated for the individual ancestor relation when stating the definition of a BTA structure, including the finiteness postulates. An analogue to postulate $U$ cannot be deduced, and plausibly so: the beginning of life may have been species-less for a long time, and completely independent species trees may have grown out of the same origin of life.

(4) It is remarkable that the conditions for species-ancestry can all be expressed as, albeit very long and convoluted, statements about conspecific individuals. This establishes the possibility of being a nominalist about biological species. Thus, a bit of homework from Quine's "On What There Is" could finally be done. ${ }^{23}$ Although nominalism about species is possible, the fact that the reconstruction is so complicated might itself rather be an argument for accepting species.

(5) Sometimes species fuse. However, if this is deliberately disregarded as a rare phenomenon, it can be shown that no more backward branching of the ancestor relation between species is possible, but that the ancestor relation between species is semi-linear like the accessibility relation of a Prior-style modal tree.

(6) It is possible to define a non-reductionist multi-layer ontological structure with species on top, living beings in the middle and cells on the ground-floor, all of them being admitted to the domain of discourse. Now the postulates must be sorted. There are bridge principles between the different levels like: " $x$ is a species iff it has members" (while members must be living beings, or " $x$ is a living being iff it at least one $y$ is a cell of $x " 24$ ). There is a far-reaching analogy between the relations between living beings and species on the one hand and the relations between cells and living beings on the other. Just as there is the extension of a species there is the cell-extension of a living being: the set of all cells that ever belonged to it. There is an ancestor relation for cells which intuitively satisfies the BTA postulates. Just as life as a whole may be imagined as a huge ancestral network of living beings, life may be imagined as an ancestral network of cells. Cell-extensions of organisms are themselves coherent subnets of this structure (often huge, though minimal in the case of unicellular living beings, whose cell extensions are their singletons). It is now possible to define what BTA took as basic, i.e. the ancestor relation between living beings, in terms of the ancestor relation between cells, and to do so completely analogously to

\footnotetext{
${ }^{23}$ Quine (1951), 13: "When we say that some zoological species are cross-fertile we are committing ourselves to recognizing as entities the several species themselves [...]. We remain so committed at least until we devise some way of so paraphrasing the statement as to show that the seeming reference to species on the part of our bound variable was an avoidable manner of speaking."

${ }^{24}$ Viruses are tricky in this respect.
} 
the way the ancestor relation between species is defined in terms of the ancestor relation between living beings. There are, however, good independent reasons for not being a nominalist about living beings in spite of this result. Cell-extensions which originate in one single cell are particularly interesting. For we are among those living beings whose reproductive cycle typically goes through single-cell bottlenecks. However, this is far from being a universal feature of life.

Future work might involve the following points:

(1) Adding a gene layer (which might be a difficult task).

(2) Knitting BTA structures or even multi-layered FTA structures onto histories of BST structures in their original space-time interpretation. A living being would then correspond to a small worm-shaped subset of point events of a history. ${ }^{25}$

(3) Enriching FTA structures by some explicit modeling of temporal order.

\section{Retrospect}

\subsection{The Story so Far}

Let us turn to the topic of retrospect. Here are some examples of it:

(1) There is no such thing as a photograph taken at an instant: Opening the shutter for zero seconds would be just too short to take a picture. Although cameras and human beings differ in that human beings are (self-)consciuos and cameras are not, I do not think that they differ in this respect: sensations, thoughts, feelings of awareness are time-consuming. If that is so, we experience changes in retrospect with our backs turned towards our future. ${ }^{26}$

(2) As to the problem of future contingents, Thomason-style supervaluations ${ }^{27}$ are to be preferred over all other solutions that have been proposed. Statements about future contingents lack a truth-value, while future necessities are already true; claiming that a future contingent is not only true, but even settled in advance turns out false. This is already quite a nice combination of attractive results which is not at all easy to achieve (in the 1950s Quine famously called it a fantasy). ${ }^{28}$ But there is even more to supervaluations: In the case that a certain contingent event did take place, in retrospect, it was the case that this former future contingent event was going to happen, and it is then settled that it was going to happen, although it was not necessarily going to happen. Formally, this result is achieved because if you evaluate the statement "It was going to be the case that p" post

\footnotetext{
25 These subset would probably resemble the "Vorkommnisse" in Kienzle (2007), which are, regrettably, restricted to one dimension.

${ }^{26}$ Strobach (1998), 201-234.

27 Thomason (1970).

${ }^{28}$ Quine (1953).
} 
festum you do so at a position in a branching tempo-modal structure à la Prior $^{29}$ where the event in question has occurred, so only such branches on which it has occurred are taken into account for the evaluation of the statement. This sensitivity to positions is a marvelous feature of supervaluations.

(3) This feature can be transferred to branching relativistic space-time. I have argued that, as long as it is in the space-like of a given event, even what happens at a "spatially" remote position from my position in space-time is ontologically undetermined with respect to my position, because positional necessity and contingency should be generalised to spacetime. In retrospect, however, once the position in question has entered the past light-cone of my world-line it is true to say that the event occurred. It occurred without ever having been occurring. ${ }^{30}$ Putnam, for instance, finds this absurd ${ }^{31}$; but it is plausible.

Might ontological retrospect play a role in connection with our formal theory of biological ancestry, FTA? I think so. Can it be modeled starting off from BTA structures by reintroducing a modal dimension? Here is how it might be done.

\subsection{Theory of Possible Ancestry (TPA)}

A TPA structure is a nonempty set of BTA structures $\left\{\left\langle\mathrm{D}_{\mathrm{P} 1},<_{\mathrm{P} 1}\right\rangle, \ldots\left\langle\mathrm{D}_{\mathrm{Pn}},<_{\mathrm{Pn}}\right\rangle\right\}$, which, as components of a TPA structure, will be called Possibilities (with a capital "P"), such that the following condition is satisfied:

\section{TPA $1 \forall \mathrm{x} \forall \mathrm{y} \forall \mathrm{P} \forall \mathrm{P}^{\prime}\left(\mathrm{x}<\mathrm{P} \quad \mathrm{y} \wedge \mathrm{y} \in \mathrm{D}_{\mathrm{P}^{\prime}} \rightarrow \mathrm{x}<\mathrm{P}^{\prime} \mathrm{y}\right)$}

Note that the following is clearly equivalent to TPA 1 (swop " $<$ " and " $>$ ", then " $x$ " and "y"):

$$
\text { TPA C1 } \left.\forall \mathrm{x} \forall \mathrm{y} \forall \mathrm{P} \forall \mathrm{P}^{\prime}\left(\mathrm{x}>_{\mathrm{P}} \mathrm{y} \wedge \mathrm{x} \in \mathrm{D}_{\mathrm{P}^{\prime}} \rightarrow \mathrm{x}>_{\mathrm{P}^{\prime}} \mathrm{y}\right)\right)
$$

Note furthermore that, of course, if some $\mathrm{x}$ stands to some $\mathrm{y}$ in the relation $<_{\mathrm{P}}$, then both $\mathrm{x}$ and $\mathrm{y}$ have to belong to $\mathrm{D}_{\mathrm{P}}$. So it follows from TPA 1 that

$$
\text { TPA C2 } \forall \mathrm{x} \forall \mathrm{y} \forall \mathrm{P} \forall \mathrm{P}^{\prime}\left(\mathrm{x}<\mathrm{P} \quad \mathrm{y} \wedge \mathrm{y} \in \mathrm{D}_{\mathrm{P}^{\prime}} \rightarrow \mathrm{x} \in \mathrm{D}_{\mathrm{P}^{\prime}}\right)
$$

Finally, note that TPA C2 may be rewritten, using the import / export law of propositional logic, as

$$
\text { TPA C3 } \forall \mathrm{x} \forall \mathrm{y} \forall \mathrm{P} \forall \mathrm{P}^{\prime}\left(\mathrm{x}<\mathrm{P} \quad \mathrm{y} \rightarrow\left(\mathrm{y} \in \mathrm{D}_{\mathrm{P}^{\prime}} \rightarrow \mathrm{x} \in \mathrm{D}_{\mathrm{P}^{\prime}}\right)\right)
$$

which yields, by contraposition,

\footnotetext{
${ }^{29}$ Prior (1967), chap. 7.

${ }^{30}$ Strobach (2007a). Summary: Strobach (2007b), cf. also Müller and Strobach (2011).

${ }^{31}$ Putnam (1967).
} 
TPA C4 $\forall \mathrm{x} \forall \mathrm{y} \forall \mathrm{P} \forall \mathrm{P}^{\prime}\left(\mathrm{x}<_{\mathrm{P}} \mathrm{y} \rightarrow\left(\mathrm{x} \notin \mathrm{D}_{\mathrm{P}^{\prime}} \rightarrow \mathrm{y} \notin \mathrm{D}_{\mathrm{P}^{\prime}}\right)\right)$

which yields, again by import / export,

TPA C5 $\forall \mathrm{x} \forall \mathrm{y} \forall \mathrm{P} \forall \mathrm{P}^{\prime}\left(\mathrm{x}<\mathrm{P} \quad \mathrm{y} \wedge \mathrm{x} \notin \mathrm{D}_{\mathrm{P}^{\prime}} \rightarrow \mathrm{y} \notin \mathrm{D}_{\mathrm{P}^{\prime}}\right)$.

To underline the similarity between BST and TPA in spirit, if not in technical detail, one might say that $\mathrm{a}$ is a choice individual between $\mathrm{P}$ and $\mathrm{P}^{\prime}$ iff

$$
\mathrm{a} \in \mathrm{D}_{\mathrm{P}} \wedge \mathrm{a} \in \mathrm{D}_{\mathrm{P}^{\prime}} \wedge \sim \forall \mathrm{y}\left(\mathrm{y} \gg_{\mathrm{P}} \mathrm{a} \equiv \mathrm{y} \gg_{\mathrm{P}^{\prime}} \mathrm{a}\right)
$$

TPA might be strengthened in the following way: Use BTA+U structures instead of BTA structures and add

\section{TPA $2 \exists x \forall P x \in D_{P}$}

Call the result a TPA $+\mathrm{U}$ structure. A TPA* $+\mathrm{U}$ structure is an TPA $+\mathrm{U}$ structure which, in addition to TPA 2, even satisfies the following, slightly stronger condition:

$$
\text { TPA 2* } \exists \mathrm{x} \forall \mathrm{P}\left(\mathrm{x} \in \mathrm{DP}_{\mathrm{P}} \wedge \forall \mathrm{y}\left(\sim \exists \mathrm{z} \mathrm{z}<\mathrm{P} \text { y } \rightarrow \mathrm{x} \geq_{\mathrm{P}} \text { y }\right)\right)
$$

The very same individual may be a member of the domains of different Possibilities of a TPA structure. Condition TPA 2 even ensures that this is the case for at least one individual. Possibilities are not maximal directed subsets. There is no single ancestor relation across Possibilities, but there is a whole family of them, one per Possibility, which satisfies the usual BTA+U conditions. They are, however, closely related.

Roughly speaking, Possibilities of TPA structures are possible worlds. If you have a close look at them, though, they turn out to be less fine-grained than possible worlds, for there are more properties of living beings than just having such and such descendants. However, TPA structures focus entirely on this property. So different Possibilities in a TPA structure are alternatives in terms of offspring and in terms of nothing else.

The user of TPA structures should be willing to confess to a certain naïvité concerning future and/or possible individuals, at least while using these structures. Anyway, in different Possibilities, different things happen, and thus different individuals exist: In $\mathrm{P}_{1}$ a has children $\mathrm{b}$ and $\mathrm{c}$ with $\mathrm{d}$ and no children with anyone else; in $\mathrm{P}_{2}$ a stays single and never has children; in $\mathrm{P}_{3}$ a marries e instead of $\mathrm{d}$ and has children $\mathrm{f}$ and $\mathrm{g}$ with $\mathrm{e}$; in $\mathrm{P}_{4}$ a marries and has children $\mathrm{b}$ and $\mathrm{c}$ with $\mathrm{d}$ plus another child with $\mathrm{h}$; in $\mathrm{P}_{5}$ a has a child $\mathrm{c}$ with $\mathrm{d}$, but no $\mathrm{b}$ makes it to existence; in $\mathrm{P}_{6} \mathrm{a}$, instead of having children $b$ and $\mathrm{c}$ with $\mathrm{d}$, has children $\mathrm{j}$ and $\mathrm{k}$ with $\mathrm{d}$. TPA structures allow for all that. However, they respect the Kripkean idea of the necessity of origin, ${ }^{32}$ because it is highly plausible: If a is b's ancestor, a will not just exist in any Possibility in which b exists, but will also be b's ancestor in any such Possibility (TPA 1). TPA C1 says: If $\mathrm{b}$ is a descendant of $\mathrm{a}$ in $\mathrm{P}_{1}$ and $\mathrm{b}$ exists in $\mathrm{P}_{2}, \mathrm{~b}$ must also be a descendant of $\mathrm{a}$ in

\footnotetext{
32 Kripke (1980), 112f.
} 
$\mathrm{P}_{2}$. It may, however, happen, that $\mathrm{b}$ is a descendant of $\mathrm{a}$ in $\mathrm{P}_{1}$ and $\mathrm{b}$ does not exist in $\mathrm{P}_{2}$. In that case, $\mathrm{b}$ is, of course, not a descendant of $\mathrm{a}$ in $\mathrm{P}_{2}$. In fact, the minimal deviation of two Possibilities would be that some individual just has one descendant less, everything else being equal. If a exists in $\mathrm{P}^{\prime}$, so must all of a's ancestors (TPA $\mathrm{C} 3$ ). For anyone with different ancestors could not be $a$. If a doesn't exist in P, neither will any of a's descendants (TPA C4). For they could not fail to be descendants of a.

TPA 2 postulates that there is at least one individual that exists in all Possibilities of the structure. Because of TPA 1 it cannot do so on its own if it has any ancestors, but they will exist in all Possibilities, too. So, as the prior choice principle in BST guarantees coherence of histories (according to the original interpretation), TPA 2 guarantees coherence of Possibilities in TPA+U structures.

Can we carve alternatives out of the structure rather than investing them? Answering this question is the topic of the postscript to the present chapter.

\subsection{The Growth of Life Itself}

TPA $2 *$ implies TPA 2 , but is stronger. Both postulates do not differ if there is a primordial cell. But if there are several ancestor-less individuals, TPA $2 *$ can be false while TPA 2 is true. For TPA $2 *$ postulates that all Possibilities have an individual in common which comes so late that all ancestor-less individuals are among its ancestors: a first common descendant of all origins of life.

This takes us back to a curious consequence of postulate $U$, the postulate of the unity of life. Consider a BTA+U structure with several ancestor-less individuals. Consider an "early" substructure of it, which does not yet contain a common descendant of all of them. This substructure will be a BTA structure, but not a BTA+U structure.

How are we to interpret this result? Here is a suggestion (maybe controversial): Before the occurrence of a first universal descendant, life did not exist. But neither did it come into being when a first universal descendant occurred. Rather, once the first universal descendant occurred, it happened that, in retrospect each of its ancestor-less ancestors became an origin of life, and life started with the earliest of them.

\subsection{Speciation}

How about adding conspecifity to TPA structures? Clearly, an TPA+CS structure would have to be a set of BTA+CS structures which satisfy at least the same constraints as the components of TPA structures. A natural question to ask is: Should there be a bridge principle which makes species membership an essential property, just as suggested by some famous examples in Kripke's Naming and Necessity? ${ }^{33}$

${ }^{33}$ Kripke (1980), 125f., 147. 
Given the rest of TPA $+\mathrm{CS}$, such a principle is easy to state. Let us call it the principle of species membership as an essential property, SMEP:

$(\mathrm{SMEP}) \forall \mathrm{x} \forall \mathrm{y} \forall \mathrm{P} \forall \mathrm{P}^{\prime}\left(\mathrm{x} C \mathrm{~S}_{\mathrm{P}} \mathrm{y} \wedge \mathrm{x} \in \mathrm{D}_{\mathrm{P}^{\prime}} \wedge \mathrm{y} \in \mathrm{D}_{\mathrm{P}^{\prime}} \rightarrow \mathrm{x} \mathrm{CS}_{\mathrm{P}^{\prime}} \mathrm{y}\right)$

If $\mathrm{x}$ and $\mathrm{y}$ belong to the same species in $\mathrm{P}$ and both exist in $\mathrm{P}^{\prime}$, they also belong to the same species in $\mathrm{P}^{\prime}$. That this renders the intuition that species membership is essential becomes particularly clear in cases where $\mathrm{x}=\mathrm{y}$. But should SMEP be added as a postulate? Kripke is right in that I could not possibly be a lion. Still, there is some reason for rejecting the principle that has just been stated. ${ }^{34}$

Take a couple of birds that makes it to a remote island. They are the beginning of a founder population which flourishes and, after a while, diverges so considerably from their mainland cousins that they could not mate with them any longer, so a new species was born. Are there any first members of the new species? According to the story just told, I should say that the first two birds on the island are good candidates. But they do not differ in any way from their direct ancestors on the mainland, so must they not belong to the same species as their ancestors do? My favorite account of the situation is this: If they had not founded the new population they would have belonged to the same species as their parents. But since they did, they don't. That is, in $\mathrm{P}_{1}$ they don't, which is supposed to be an alternative in which they were successful founders. They become the first members of a new species in retrospect, once the new species has developed. But once it has, it is true that the new species started with them and not any later. But take $\mathrm{P}_{2}$ in which they starve on the island without leaving any descendants. Clearly, in $\mathrm{P}_{2}$ they belong to the same species as their parents. So species membership is not an essential property, but may vary from possible world to possible world. So SMEP should not be a postulate of TPA+CS. Should we even say in retrospect that the founders changed species membership during their lifetime? Probably we should.

\subsection{Individual Ontogeny}

Let us switch to the cell level. BTA can be extended to a multi-layer FTA that includes a cell level. What would its modal version, a TPA with cells, look like? Again, a natural question is if there is any cross-Possibility bridge principle. My proposal is that there is at least one such a principle, but that it is weaker than the one that first comes to mind. According to Kripke, there is a microscopic version of the principle of the necessity of origin. ${ }^{35}$ I could not have originated from a different sperm and egg. Let us focus on living beings like us whose reproductive cycle includes single-cell bottlenecks. Let us define what a first cell is. The definition presupposes the relation

\footnotetext{
34 The story ignores vague boundaries. That might be a mistake. Perhaps species talk functions pretty differently at the end of the day.

35 Kripke (1980), 112f.
} 
CellOf, which, in turn, holds only between a cell and a living being and is structurally similar to the relation of species membership:

$$
\mathrm{x} \text { FCO } \mathrm{y} \text { iff } \mathrm{x} \text { CellOf } \mathrm{y} \wedge \sim \exists \mathrm{z}(\mathrm{z}<\mathrm{x} \wedge \mathrm{z} \text { CellOf } \mathrm{y})
$$

Once we move on to the modal version, all the relations have Possibility parameters. Now consider the following principle:

(origin1) $\forall \mathrm{x} \forall \mathrm{y} \forall \mathrm{P} \forall \mathrm{P}^{\prime}\left(\mathrm{x} F C O_{\mathrm{P}} \mathrm{y} \rightarrow\left(\left(\mathrm{x} \in \mathrm{D}_{\mathrm{P}^{\prime}} \equiv \mathrm{y} \in \mathrm{D}_{\mathrm{P}^{\prime}}\right) \wedge\left(\mathrm{x} \in \mathrm{D}_{\mathrm{P}^{\prime}} \rightarrow \mathrm{x} \mathrm{FCO}_{\mathrm{P}^{\prime}} \mathrm{y}\right)\right)\right)$

If $\mathrm{x}$ is a first cell of $\mathrm{y}$ in $\mathrm{P}$, then $\mathrm{x}$ and $\mathrm{y}$ either coexist or both fail to exist in any $\mathrm{P}^{\prime}$, and if $\mathrm{x}$ exists in $\mathrm{P}^{\prime}$, $\mathrm{x}$ is a first cell of $\mathrm{y}$ in $\mathrm{P}^{\prime}$, too. So clearly, in every alternative in which y exists, $\mathrm{x}$ is its first cell; and in every alternative which $\mathrm{x}$ exists, $\mathrm{y}$ exists already because x exists, being y's first cell.

While it is nice that this principle can be stated within the framework that has been presented so far, I think it is too strong to merit acceptance. Like in the cases of life or speciation, something might have to reach a certain size before y exists. If y comes into existence, nothing speaks against some cell's being y's first cell in retrospect which would otherwise not have been a cell of any living being. I started from a zygote, which is the first cell of the set of all cells that were, are or will be cells of my body. After things turned out fine it is even true to say that $I$ started of as a zygote. But only in retrospect. Had the blastula into which the same zygote turned by cell division been destroyed I would never have existed. This is no contradiction. The point may have implications for moral philosophy, which might concern PID or the very difficult issue of abortion. I shall not pursue them here. But let me state a weaker principle than the one above, which I do think is plausible at least in connection with single-cell bottlenecks:

$$
\text { (origin 2) } \forall \mathrm{x} \forall \mathrm{y} \forall \mathrm{P} \forall \mathrm{P}^{\prime}\left(\mathrm{x} \mathrm{FCO}_{\mathrm{P}} \mathrm{y} \wedge \mathrm{y} \in \mathrm{D}_{\mathrm{P}^{\prime}} \rightarrow \mathrm{x} \in \mathrm{D}_{\mathrm{P}^{\prime}} \wedge \mathrm{x} \mathrm{FCO}_{\mathrm{P}^{\prime}} \mathrm{y}\right)
$$

If y exists in $P^{\prime}$, then so must $\mathrm{x}$, and $\mathrm{x}$ must be first cell of $\mathrm{y}$ in $\mathrm{P}^{\prime}$, too. But this does not rule out a Possibility in which y never exists and $\mathrm{x}$ exists but isn't the first cell of anything. ${ }^{36}$

\section{Afterthought: Resuscitation and Decisions}

To conclude, let me mention two more possible applications of the idea of ontological retrospect.

\footnotetext{
36 The same point is argued in Strobach (2010) without explicit modal modeling. Possibilities are quite useful to clearly state the difference between the two positions, which can only be done using a version of TPA.
} 
(1) The first example is related to biology. Perhaps it is outdated in the days of brain death. The idea goes like this: It is a world-relative matter (in terms of temporally structured possible worlds) whether or not a certain event is the death of a certain living being. If a patient is successfully resuscitated the very same event will not be the patient's death which, if resuscitation fails, will in retrospect be the patient's death in the sense that that was when the patient died.

(2) The last example is about decisions. At least, it belongs to the range of the common use of the term "decision", although it is probably not about anything which is called a decision in connection with STIT models. It is about a mental state which will, later on, be called the decision or perhaps, more cautiously, "what I felt the moment when I knew I had made up my mind". It is not completely far-fetched to call a decision what I remember as one. I claim that, in this sense of the word "decision", decisions are retrospective events, i.e. events which acquire the status of being decisions only in retrospect and contingently. One might think that a decision in this sense necessitates the action. But this is actually not true: "Only the execution of the intention provides it with the stamp 'decision', , says Schopenhauer ${ }^{37}$. Never mind that Schopenhauer was wrong in that he was a determinist. ${ }^{38}$ This is a point he got right: As long as nothing has been done, someone or something might interfere, or I might interfere by hesitating and suddenly starting to reconsider and reevaluate. If nobody and nothing interferes and I act, my "decisive feeling" becomes the decision in retrospect. Then that was indeed when I decided. If something interferes the very same mental event never made it to be a decision. So the same event may be a decision in one possible world history and not be one in another.

\section{Summary}

To sum up, I have argued (1) that a certain subclass of FTA structures is identical with a certain subclass of BST structures; (2) that the feature of FTA which formally corresponds to the prior choice principle of BST is a fundamental principle of the unity of life; (3) that the basic theory of ancestry BTA may modalised in such a way that it incorporates the principle of the necessity of origin; (4) that an account of speciation along the lines I have suggested calls into doubt the idea that species-membership is always an essential property; (5) that retrospect is an ontological feature of reality; (6) that the beginning of life on earth, speciation, individual ontogeny, death and decisions involve retrospect.

Open Access This chapter is distributed under the terms of the Creative Commons Attribution Noncommercial License, which permits any noncommercial use, distribution, and reproduction in any medium, provided the original author(s) and source are credited.

\footnotetext{
${ }^{37}$ Schopenhauer (1818), 152 [WWV I 1 §18]: "Nur die Ausführung stämpelt den Entschluss, der bis dahin noch immer veränderlicher Vorsatz ist".

${ }^{38}$ Schopenhauer (1839), 372-383 [section II].
} 


\section{References}

Belnap, N. 1992. Branching space-time. Synthese 92: 385-434.

Belnap, N., M. Perloff, and M. Xu. 2001. Facing the Future. Oxford: Oxford University Press.

Carnap, R. 1958. Introduction to symbolic logic and its applications. New York: Dover (translation of Einführung in die symbolische Logik. Wien: Julius Springer 1954).

Crossley, J.L., and I.M. Humberstone. 1977. The logic of 'Actually'. Reports on Mathematical Logic 8: 11-29.

Goranko, V., A. Montanari, and G. Sciavicco. 2004. A road map of interval temporal logics and duration calculi. Journal of Applied Non-Classical Logics 14(1/2004): 1-48.

Gusfield, D. 2007. Algorithms on strings, trees, and sequences, 10th ed. Cambridge: Cambridge University Press.

Kienzle, B. 2007. Die Bestimmung des Janus. Tübingen: Mohr Siebeck.

Kripke, S. 1980. Naming and necessity. Oxford: Blackwell.

McTaggart, J.M.E. 1908. The unreality of time. Mind 18: 457-484.

Müller, T., and Strobach, N. (2011). A letter on the present state of affairs. Prior, indeterminism and relativity 40 years later. Synthese. Preprint online at Springerlink: doi:10.1007/s11229-0119939-z.

Müller, T. (2011). Branching space-times, general relativity, the Hausdorff property, and modal consistency. Preprint: http://philsci-archive.pitt.edu/8577/1/bst_hausdorff20apr11.pdf.

Prior, A. 1967. Past, Present and Future. Oxford: Oxford University Press.

Putnam, H. 1967. Time and physical geometry. Journal of Philosophy 64: 240-247.

Quine, W.V.O. 1951. On what there is. In: From a logical point of view, 1-19. Cambridge/Mass: Harvard University Press.

Quine, W.V.O. 1953. On a so-called paradox. Mind 62: 65-67.

Schopenhauer, A. 1818. Die Welt als Wille und Vorstellung I [The World as Will and Representation volume I]. In: Arthur Schopenhauers Werke in fünf Bänden, ed. Ludger Lütkehaus, Zürich: Haffman 1988.

Schopenhauer, A. 1839. Preisschrift ueber die Freiheit des menschlichen Willens. Volume 3 of the same edition, 359-458.

Strobach, N. 1998. The moment of change - A systematic history in the philosophy of space and time. Dordrecht: Kluwer.

Strobach, N. 2007a. Alternativen in der Raumzeit - eine Studie zur philosophischen Anwendung multimodaler Aussagenlogiken. Berlin: Logos.

Strobach, N. 2007b. Fooling around with tenses. Studies in the History and Philosophy of Modern Physics 38(3): 653-672.

Strobach, N. 2010. Zellen in der Logik des Lebens. In: Logos, Freie Zeitschrift für wissenschaftliche Philosophie. 2 (2010), 2-51. http://fzwp.de/0002/urn:nbn:de:0265--00022.

Strobach, N. 2011. Die Persistenz der biologischen Arten. Provisorische Überlegungen zu einer biologischen Interpretation zeitlogischer Strukturen. In: Persistenz-Indexikalität-Zeiterfahrung, ed. P. Schmechtig and G. Schönrich, 371-403. Heusenstamm: Ontos.

Strobach, N. (forthcoming). 2013. Aristoteles und die Konstanz der Arten. Forthcoming in the proceedings volume to a conference on Aristotle's biology at Kassel University in 2009, ed. G. Heinemann and R. Timme. Freiburg: Alber.

Thomason, R. 1970. Indeterminist time and truth-value gaps. Theoria 36: 264-281.

Woodger, J.H. 1937. The Axiomatic Method in Biology. With Appendices by Alfred Tarski and W. F. Floyd. Cambridge: Cambridge University Press. 